\title{
Garantias externas e fundamentos internos \\ Dimensões da legitimidade em Max Weber
}

Carlos Eduardo Sell*

https://orcid.org/0000-0002-3281-7045

O conceito de legitimidade constitui uma das principais heranças de Max Weber na teoria social e política contemporânea. Visando a recuperar seu significado, este artigo propõe uma reconstrução histórico-sistemática do conceito em dois âmbitos diferentes de Economia e sociedade, a saber: aquele que trata da sociologia compreensiva em geral e aquele que trata especificamente da sociologia política da dominação. Com efeito, existem diferenças substanciais no modo como a questão da legitimidade é tratada em cada um destes âmbitos. Ocorre que, em seus Conceitos sociológicos fundamentais [capítulo 1], Weber apresenta diferentes listagens que parecem não combinar: ele começa com os quatro tipos de ação social; elenca depois cinco tipos de garantias de legitimidade; e, ao final, discorre sobre quatro motivos internos que fundamentam a legitimidade. Como esse complexo quadro de conceitos sociológicos está relacionado com os três tipos puros de dominação legítima [Capítulo 3 - Os tipos de dominação]?

Tais discrepâncias vão muito além do aspecto redacional, e suas implicações teóricas suscitaram diversas tentativas de análise, mas não se encontrou consenso na literatura especializada a esse respeito (Speer, 1978; Prewo, 1979; Schluchter, 1988; Bader, 1989; Lübbe, 1991). Diante de tamanha confusão, Breuer (2006) entende que se deva abandonar a tentativa de forjar uma coerência rígida entre as listagens

* Universidade Federal de Santa Catarina, Florianópolis, Brasil. 
acima, como se houvesse uma conexão direta entre os tipos de ação social, os tipos de dominação, os motivos internos e os fundamentos externos da legitimidade. Dessa forma, fica aberto o caminho para que, mais do que nexos histórico-textuais, possamos nos concentrar na análise do vínculo analítico-sistemático entre esses capítulos e seus múltiplos conceitos. Mais especificamente, ao invés de nos concentrarmos na análise exegética, podemos voltar nossa atenção para os problemas hermenêuticos que estão implicados nessa diferença.

Seguindo essa pista, este artigo discute o entrelaçamento entre o aspecto estrutural e o aspecto simbólico da dominação. O que se pretende é uma aproximação ao conceito de legitimidade isento de sua redução unilateral-idealista ao aspecto da crença (Merquior, 1990). Mostra-se, assim, que, embora a legitimidade diga respeito especificamente à dimensão normativa das instituições, o conjunto da dominação não se limita apenas a um conjunto de crenças compartilhadas, dado que tais representações necessitam de sua institucionalização em estruturas organizacionais específicas, além de estarem radicadas na esfera da atribuição subjetiva de sentido.

Em função deste objetivo, o artigo será organizado na seguinte forma. $\mathrm{Na}$ primeira parte (histórica), examina-se o conceito de legitimidade no contexto da sociologia politica de Weber. Com base na história de redação dos dois capítulos sobre a dominação existentes em Economia e sociedade, retoma-se o debate entre os intérpretes sobre como Weber avaliou o peso causal da dimensão estrutural e da dimensão simbólica da dominação no processo de redação de seus escritos. Recusando a hipótese de uma ruptura interpretativa, segundo a qual Weber transita de uma visão estruturalista para uma visão idealista, defende-se que ambos os fatores sempre foram concebidos por ele como elementos codeterminantes, representando aspectos distintos e complementares da dominação.

Após examinar o peso analítico das dimensões organização/representação na sociologia da dominação de Weber, passaremos, em âmbito mais restrito, a considerar o modo de relação entre essas duas dimensões. Partindo do primeiro capítulo de Economia e sociedade (Conceitos sociológicos fundamentais), examinaremos, inicialmente, o núcleo teórico do conceito de legitimidade, diferenciando entre a vigência empírico-factual e a validade normativo-ideal das instituições. Tal passo nos permitirá, a seguir, diferenciar entre as garantias externas (dimensão macro) e os fundamentos internos da legitimidade (dimensão micro).

A conclusão é que a dupla conceitual "forma/garantias" "espírito/fundamentos" aponta para diferentes dimensões da legitimidade. Portanto, ao propor um conceito de legitimação que entrelaça a dimensão interna à dimensão externa da dominação, Weber plantou os alicerces de um conceito multidimensional de legitimidade cujos parâmetros ainda permanecem válidos no cenário teórico contemporâneo. 
A sociologia da dominação de Weber não nasceu ex abrupto e exigiu dele um longo processo de reflexão e amadurecimento. À luz da republicação dos escritos weberianos (o projeto editorial Max Weber Gesamtausgabe - doravante MWG) e da densa exegese que a acompanha, sabemos atualmente que o pensador apresentou sua tríade da dominação em vários textos, que cobrem sua última década de vida. Podemos documentar pelo menos oito momentos diferentes em que Weber se reporta, em maior ou menor grau, a essa tipologia (conforme exposto em MWG I/24)․․

No entanto, os textos mais importantes para acompanhar o processo reflexivo de Weber são os dois capitulos sobre a sociologia da dominação que estão localizados na primeira e na segunda partes daquela publicação mundialmente famosa e bem-sucedida que passou à história com o nome - provavelmente equivocado - de Economia e sociedade. Essa imensa massa de escritos, como hoje está demonstrado [MWG I/24], não é nenhum "livro" coerente e sistemático, dividido em duas partes, como estamos acostumados a imaginar, mas um "projeto" complexo, descontínuo e multifacetado de investigação que pode ser dividido, grosso modo, em duas grandes etapas, separadas pela Primeira Guerra Mundial. No bojo deste processo, Weber escreveu duas versões da sociologia da dominação: o capítulo 3 ("Os tipos de dominação") da quinta edição de Economia e sociedade é mais recente e foi redigido por Weber depois da guerra; enquanto o capítulo 9 da segunda parte ("Sociologia da dominação"), muito mais extenso e histórico-descritivo, foi produzido por ele ainda no início de suas pesquisas sobre o assunto (em torno de 1909).

1. A trilogia das formas da dominação ainda não aparece no primeiro plano de redação de Economia e sociedade, concebido em 1910 no "Plano de distribuição material" (Stoffverteilungsplann - MWG I/24, p. 75), mas apenas em 1914, na assim chamada "Divisão do conjunto da obra” (Einteilung des Gesamtwerkes - MWG I/24, p. 169). Também podemos encontrar o assunto nas anotações de aula (MWG III/7) preparadas por Weber para seus alunos, em Munique, em 1920. Mas essas são menções muito breves e, além de ambos os capítulos de Economia e sociedade, a primeira exposição sistemática só aparece em um escrito de 1915 dedicado à religião e que recebe o título de Introdução (1915) (MWG I /19, pp. 119-125). Existe também um manuscrito póstumo, publicado em 1922, e cuja data de redação é incerta ("Os tipos de dominação"). Não podemos esquecer ainda as descrições que Weber faz em Política como profissão (MWG I/17), além de uma conferência datada de 1918 (Problemas de sociologia do Estado), na qual o tema volta a ser tratado com a inclusão (depois abandonada) de um quarto tipo de dominação: a forma democrática. 


\section{0 problema histórico-interpretativo: duas sociologias políticas?}

Dois capítulos sobre a dominação em Economia e sociedade? Na verdade, duas versões, $\mathrm{e}^{2}$ nesse processo de amadurecimento são notáveis as correções, inovações, acréscimos e supressões, que podemos identificar entre as diferentes versões da sociologia da dominação, não apenas em pequenos detalhes, mas em elementos centrais do seu esquema teórico, tema que, infelizmente, não poderemos abordar aqui (maiores detalhes em Hanke, 2001).

Em que medida essas transformações gerais afetaram, em particular, o conceito de legitimidade? Quanto a este ponto, Edith Hanke (2001), que é nada menos que a organizadora do número da MWG dedicado à fase antiga da sociologia da dominação, é da opinião de que a legitimidade modifica seu lugar e sua importância no esquema geral de Weber. Segundo a intérprete, o Weber da primeira fase parece revelar uma compreensão estrutural-objetivista da dominação. É somente no período pós-guerra que o elemento cultural-simbólico da legitimidade adquire um lugar central.

Examinando os textos escritos por Weber ainda antes da grande guerra, Hanke salienta o fato de que Weber pretende, como ele mesmo diz, examinar "a dominação por meio da 'organização' " (MWG I/22-4, p. 6). Em função dessa preocupação, ele entende que "a estrutura de uma dominação recebe seu caráter sociológico da natureza geral da relação entre o governante ou os governantes e seu aparato administrativo, e entre estes dois e os dominados, e, além disso, de seus princípios específicos de dominação" (MWG I/22-4, p. 10). É somente em trecho posterior que ele faz referência “aos princípios últimos em que pode apoiar-se a 'validade’ de uma dominação" (MWG I/22-4, p. 10). Portanto, é somente em segundo lugar que ele se remete ao problema da legitimidade propriamente dito. As justificativas da dominação seriam aquelas responsáveis pela "subsistência de toda dominação" e, dentre elas, Weber nomeia 1) um sistema de regras racionais estatuídas, bem como 2) a autoridade pessoal, seja ela baseada na tradição ou na crença no carisma. Segue, enfim, uma lista dos tipos de dominação; mas, longe de resultarem dos princípios de legitimidade, eles parecem ser definidos muito mais em termos estruturais do que simbólicos:

Quando a ação social de uma formação de dominação se baseia numa relação associativa racional, encontra seu tipo específico na "burocracia”. A ação social, numa situação vinculada a relações de autoridade tradicionais, está tipicamente representada pelo "patriarcalismo". A

2. Em 16 de maio de 1916, Weber escreve ao editor: "Minha Sociologia. Deus do céu! Eu já ficaria contente se durante esta guerra eu conseguir terminar os artigos sobre 'A ética econômica das religiões mundiais' para que você possa publicá-las juntamente com a 'Ética protestante'” (MWG II/9, p. 411). 
formação de dominação carismática apoia-se na autoridade não racionalmente nem tradicionalmente fundamentada de personalidades concretas (MWG I/22-4, p. 11).

Esta trilogia estrutural (burocracia/patriarcalismo/dominação carismática) contrasta com a terminologia bem mais uniforme que vamos encontrar no texto pós-guerra de Weber. Nesta fase, como sabemos, Weber afirma que "existem três tipos puros de dominação legítima”, e isso a depender da "validade da legitimidade" (MWG I/23, p. 154), que pode ser: 1) de caráter racional (dominação legal), 2) de caráter tradicional (dominação tradicional) ou de caráter carismático (dominação carismática). Logo, em sua segunda fase, Weber parece inverter o peso dos fatores determinantes de sua tipologia, pois "dependendo da natureza da legitimidade pretendida diferem o tipo de obediência e do quadro administrativo destinado a garanti-la, bem como o caráter do exercício da dominação”. Ele conclui, portanto, que "é conveniente distinguir as classes de dominação segundo suas pretensões típicas à legitimidade" (MWG I/23, p. 152).

Estamos, pois, diante de um Weber estruturalista na primeira fase e cultural-idealista na segunda? Essa não é a opinião de Stefan Breuer (2006 e 2011), que, mesmo admitindo duas "fases" distintas na sociologia de Weber, entende que ele chegou a uma versão definitiva sobre os tipos dominação ainda antes da Primeira Guerra. Mesmo que no escrito Sobre algumas categorias da sociologia compreensiva, de 1913 (MWG I/18), Weber se referisse apenas às ordens que repousam sobre uma legitimidade consensual [Einverständnishalndeln], na primeira versão da sociologia da dominação (pré-guerra) ele já tem definitivamente elaborada sua tipologia das estruturas de dominação. Na fase seguinte (pós-guerra), os fundamentos do esquema da dominação já estavam plenamente estabelecidos. O problema é que Breuer não se coloca o problema do peso causal e não chega a discutir o modo de relação entre as variáveis estrutura/cultura na sociologia da dominação de Weber.

Tal questão não ficou fora do radar de Wolfgang Schluchter, que sustenta a opinião de que é apenas na segunda versão de seu texto que Weber "alinha, de modo consequente, os princípios de legitimação com as formas de administração” (Schluchter, 2016, p. 277). Ele acrescenta ainda que "estes dois aspectos, ambos determinantes para a estrutura da dominação, não são novidade em sua obra, embora a utilização consequente de ambos para a distinção dos tipos puros de dominação o seja” (Schluchter, 2016, p. 278). Resta saber o que Schluchter quer dizer quando afirma que foi apenas tardiamente que Weber foi realmente "consequente" no balanço entre princípios de legitimação e formas de administração. 


\section{0 problema analítico: a questão da correspondência}

A controvérsia interpretativa acima esboçada não constitui apenas uma filigrana de pesquisadores hiperespecializados. Ela vai bem além do caráter histórico e nos traz à tona um problema analítico da maior importância. Ele diz respeito à natureza global do esquema analítico de Weber e nos remete à questão teórica da relação entre a dimensão estrutural e a dimensão simbólica da dominação. Mesmo admitindo-se que estrutura (Organização) e legitimidade (Representação) são ambos elementos constitutivos da ordem política, resta que definir os tipos dominação a partir da legitimidade sugere a predominância causal do fator simbólico sobre o fator estrutural. A impressão que surge é que as estruturas são unilateralmente derivadas de representações simbólicas, o que deixaria Weber exposto à crítica de que seu esquema resvala na direção de reducionismo idealista, como já sustentava, por exemplo, José Guilherme Merquior (1990).

Para refutar esse tipo de leitura, recorro à celebre conferência proferida por Weber em 28 de janeiro de 1919: Política como profissão [MWG I/17]. A despeito de seu caráter mais passional - visto que alocução pública e não um escrito técnico-acadêmico -, aqui Weber parece ter achado uma expressão do problema da relação estrutura/representação menos exposto às ambiguidades de redação que ainda encontramos nas duas versões de Economia e sociedade.

Em sua alocução, Weber parte da premissa de que todas as associações políticas (incluído o Estado) constituem formas de dominação dos seres humanos sobre humanos, levando-nos à seguinte questão: "em que justificações internas e em que meios externos está apoiada a dominação?” (MWG I/17, p. 36). A formulação, segundo se pode ver, não apenas elide qualquer prioridade causal entre esses dois elementos, como também deixa transparecer qual o critério de distinção entre a dominação concebida enquanto organização e a dominação entendida enquanto legitimidade, a saber: a diferenciação entre interno versus externo, ou, ainda, entre justificativas versus recursos. Na sequência do texto, ao examinar ambos os fatores, Weber evita qualquer tipo de reducionismo e analisa o papel causal de cada um deles sem qualquer forma de subordinação.

Em relação às “justificativas internas”, ele retoma a tríade que já conhecemos, desta feita enumeradas pela ordem de dominação tradicional, dominação carismática e dominação em virtude da legalidade. Trata-se de "três fundamentos que dão legitimidade a uma dominação" ou, em outra formulação, eles constituem as "razões da legitimidade da obediência” (MWG I/17, p. 37).

Contudo, a dominação depende também "da natureza dos recursos de que se dispõem" (MWG I/17, p. 38). De fato, para impor sua obediência, os governantes 
necessitam "dispor daqueles bens materiais que eventualmente possam ser necessários para se impor pela força física” (MWG I/17, p. 38). Weber é bastante preciso na enumeração desses meios que são "um quadro administrativo pessoal e meios de administração objetivos" (Idem). O quadro administrativo está vinculado ao governante muito mais por interesses (remuneração material e honra social) do que pelas concepções de legitimidade. Ademais, não se pode esquecer que para "a manutenção de qualquer dominação coercitiva são necessários certos bens materiais palpáveis, dentre os quais Weber elenca o "dinheiro, edifícios, material bélico, lotes de veículos, cavalos etc." (MWG I/17, p. 39).

Com base nesses elementos estruturais, Weber nos oferece uma nova tipologia afirmando que todas as ordens estatais podem ser classificadas segundo dois princípios básicos. A existência de uma tipologia estrutural independente do fator da representação é, aqui, de importância decisiva: é ela que nos indica que o aspecto estrutural/organizacional da dominação não é uma espécie de emanação que deriva de suas justificativas simbólicas. Na primeira categoria apresentada por Weber, o quadro administrativo "é ele mesmo o proprietário dos meios administrativos", enquanto na segunda categoria "o quadro administrativo está separado dos meios materiais de produção" (Idem). Resulta daí que na primeira categoria encontramos as associações estamentalmente estruturadas, em particular o feudalismo; enquanto na segunda categoria estão incluídos a dominação patriarcal e patrimonial, o despotismo sultânico e a ordem estatal burocrática.

Embora a exposição de Política como profissão deixe mais clara a independência causal dos fatores estrutural e simbólico na configuração dos tipos de dominação, evitando assim a armadilha da subordinação de um elemento a outro (idealismo), o escrito não chega a esclarecer com maior exatidão como Weber concebe, efetivamente, a relação entre essas duas dimensões. Embora os âmbitos de cada uma das variáveis estejam bem delimitados, não se chega a aprofundar o modus operandi de suas conexões.

\section{A legitimidade na sociologia geral}

Para avançar no entendimento do tema da legitimidade, temos que deixar este âmbito geral para um âmbito mais específico que nos possibilite discutir o conteúdo do conceito em si mesmo. Para tanto, deslocaremos nossa discussão para o primeiro capítulo de Economia e sociedade, no qual o tema da legitimidade é retomado no contexto de sua teoria das ordens ou estruturas sociais. Isso nos permitirá determinar, com maior exatidão, o núcleo teórico do conceito de legitimidade: a saber, o conceito de validade [Geltung]. A seguir passaremos ao tratamento das garantias externas e 
dos fundamentos internos da legitimidade, distinção que nos fornecerá a chave para entender o nexo intrínseco entre a dimensão organizacional e a dimensão simbólica da legitimidade em Weber.

\section{Ordem social e ordem legítima}

Weber criticou asperamente o jurista Rudolf Stammler por confundir a vigência empírica e a validade normativa da ordem social (MWG I/23, cap. I, \$5, nota 3). Curioso é que o próprio Weber não parece distinguir com absoluta clareza a ideia da ordem social (em si) da ideia de ordem legítima (Bader, 1989, pp. 296-334). A questão central em jogo é a seguinte: toda ordem social já é legítima ou podem existir ordens sociais desprovidas desse atributo? Essa suposta confusão é agravada pelo fato de Weber não utilizar o termo Geltung com total rigor, acenando ora para a sua dimensão normativa, ora para a sua dimensão empírica. Fazendo uma alusão a Habermas (1992), Weber parece oscilar entre o entendimento de vigência como "facticidade" ou como "validade" [Geltung].

Ele começa suas explicações no parágrafo 5 do primeiro capítulo afirmando que "a validade [Gelten] de uma ordem significa para nós mais do que a regularidade do desenvolvimento da ação social condicionada pelo costume ou pela situação de interesses" (MWG I/23, cap. I, \$5, nota 1). Esse elemento “a mais" que explica a regularidade, exemplificado por um funcionário público que comparece pontualmente a sua repartição, seria exatamente a "validade", entendida no sentido de que esse comportamento é visto como um "mandamento" [Gebot] que é vivido como um "sentimento de dever" [Pflichtsgefühl].

A ideia de que Geltung é sinônimo de validade normativa parece ainda mais explícita quando, na nota explicativa seguinte, Weber destaca que a vigência das ordens ocorre quando a orientação por máximas tem como motivo também, pelos menos para uma parte dos agentes sociais, o fato de que elas "valem para a ação" [für das Handeln gelten] enquanto "modelos" [verbindlich] ou "obrigações" [vorbildlich]. Weber explica ainda que uma ordem social observada pelo hábito ou pelo interesse é muito mais instável do que uma ordem que aparece com o prestígio de ser modelar/ exemplar [Verbindlichkeit] ou obrigatória [Vorbildlichkeit]. Neste trecho, ele faz ainda o seguinte acréscimo: "ou conforme dizemos, a legitimidade". Em todas estas passagens a validade da ordem pertence sempre ao campo do "geltendsollen" (MWG I/23, cap. I, \$5) e deve ser entendida no sentido de "norma obrigatória" [verbindliche Norm] (MWG I/23, cap. I, \$5, nota 3).

No entanto, em outras passagens do parágrafo 5 o termo validade parece indicar apenas a existência factual ou mera vigência da ordem social. Por este ângulo, Gel- 
tung significa apenas que a ação social é uma função da "chance" (MWG I /23, cap. I, $\$ 5$, nota 1 ) de que o indivíduo se oriente efetivamente por uma ordem social dada. Podemos dizer também que nesta acepção Geltung assinala o fato de que uma determinada ordem social só existe (ou possui o atributo do ser) enquanto ocorrem ações sociais de determinados tipos. Partindo desta sentença, Geltung deve ser entendida na sua acepção empírico-factual como a efetividade ou a existência concreta da ordem social através de ações ou relações sociais. Nesta direção, Weber dirá, por exemplo, que "interpretações do sentido da ordem [...] possuem 'validade' [gelten] na medida em que realmente determinam as ações” (MWG I/23, cap. I, \$5, nota 3).É importante enfatizar aqui o nexo entre Geltung = efetividade, ou, como diz o próprio Weber, uma ordem social "vigora” na medida em que há a chance de que a ação realmente se oriente por ela” (MWG I/23, cap. I, \$5, nota 3). Nesta última sentença, a correlação [Geltung = efetividade/facticidade $]$ volta a ser enfatizada, ainda que não de forma automática, evidentemente, mas como chance ${ }^{3}$.

Apesar dessas oscilações terminológicas, o raciocínio de Weber só faz sentido caso o aspecto da validade normativa, por um lado, e da validez ou vigência factual, por outro, sejam claramente demarcados. Qualquer ordem social só existe enquanto persiste de forma real e efetiva a chance de que as ações sociais se orientem por um conteúdo de sentido que lhes serve de referência. Desaparecendo essa base microssociológica, desaparece também a ordem social: trata-se, pois, da vigência (factual) da ordem. Mas se toda ordem social possui o atributo da vigência empírico-factual, nem toda ordem social pode ser considerada uma ordem legítima, ou seja, nem todas as regras/máximas que a constituem orientam os indivíduos enquanto máximas exemplares ou obrigatórias. Em sentido inverso, vale dizer também que ordens sociais podem até possuir vigência em função da legitimidade, mas este nem sempre é o caso, o que nos leva à necessidade de distinguir entre tipos diferentes de ordens sociais.

Nessa linha, Greshoff (2006, p. 279) destaca que Weber diferencia entre ordens sociais observadas "apenas" em função de costumes ou interesses, por um lado, e ordens sociais que supõem a crença na legitimidade, o que nos permite distinguir ordens sociais simples de ordens sociais legitimas. No primeiro caso, os portadores das ações sociais orientam-se pelas máximas constitutivas da ordem de modo livre. Já no segundo caso, a orientação é sentida como "devendo ser válida” [geltendsollend]. Wolfgang Schluchter (2015, p. 251) também opta por uma classificação dual dos tipos de ordem, apondo a ordem social de fato à ordem legitima. Ordens sociais motivadas

3. Essa mesma ambivalência também pode ser identificada no capítulo da sociologia da dominação do pós-guerra, na qual ele afirma que "a legitimidade de uma dominação deve naturalmente ser considerada apenas uma chance de, em grau relevante, ser reconhecida e tratada praticamente como tal" (MWG I/23, p. 153, nota 1). 
por costumes constituem apenas regularidades factuais $d a$ ação e são diferentes das ações orientadas por regras ou máximas para a ação.

Diferenças à parte, resulta que agora já estamos em condições de identificar com precisão quais são os elementos que definem o núcleo do conceito de legitimidade em Weber. A legitimidade nos remete para o "dever-ser válido" [Geltensollend] na medida em que nos fornece referências modelares [Vorbindlichkeit] e obrigatórias [Verbindlichkeit] (MWG I/23, cap. I, \$5, nota 2) de ação social. Em função desse componente normativo, a legitimidade é um fator fundamental do processo de institucionalização das estruturas sociais [Stachura, 2008]. Como diz Weber, "uma ordem observada somente por motivos racionais com referência a um fim é em geral muito mais frágil [labil] do que a orientação por essa ordem unicamente em virtude dos costumes". E arremata: "esta, por sua vez, é ainda mais frágil [labil] do que uma ordem que aparece com o prestígio de ser modelar ou obrigatória ou, conforme dizemos, 'legitima”” (MWG I/23, cap.I, \$5, nota 2). De uma ordem fundada no interesse, passando pela ordem tradicional, até chegar a uma ordem legítima, o que temos é um processo crescente de estabilidade cujo ponto culminante é o atributo da normatividade.

\section{A "forma" externa e o "espírito" interno da legitimidade}

Feita a distinção entre ordens sociais em sentido geral e ordens legítimas [em sentido específico], passemos aos dois parágrafos seguintes ( $\$ 6$ e $\$ 7$ ) nos quais Weber examina os aspectos das "garantias da legitimidade" [Legitimitätgararantien] e dos "fundamentos da legitimidade" [Legitimitätsgründen]. Para dar maior inteligibilidade a essa distinção, sigo a proposta de Schwinn (2014, pp. 98-100), que procura aproximá-la da conhecida tipologia utilizada por Weber em $A$ ética protestante e o espirito do capitalismo. Conforme tal entendimento, as garantias externas correspondem aos princípios estruturais (forma) da dominação, enquanto os princípios simbólicos (espírito) resultam de um processo de atribuição que tem sua base no plano dos agentes sociais. Essa releitura tem a vantagem adicional de nos permitir demarcar com maior precisão a dimensão macro e a dimensão micro da ordem legítima (Schwinn, 1993). Mais especificamente, enquanto as garantias dizem respeito ao aspecto macroestrutural propriamente dito, a questão da atribuição [Zuschreibung] nos coloca na perspectiva dos agentes sociais, pois, como diz Weber, "a vigência legitima [é] atribuída pelos agentes a uma ordem" (MWG I/23, Cap. I, \$7). 
Elucidar as garantias "externas" da legitimidade significa voltar nossa atenção para "expectativas de determinadas consequências externas" (MWG I/23, cap. I, \$6, caput) que advêm sobre nosso agir. No centro da análise está a tentativa de entender quais são os mecanismos institucionais que, operando externamente, condicionam o agir e, desta forma, atuam como garantias da legitimidade. Segundo Weber, tais consequências variam a depender do tipo de ordem em questão, ou seja, importa observar se estamos em (a) uma situação de interesses [Interessenlage], (b) da convenção (c) ou do direito. Isso significa que os efeitos estruturais variam conforme estivermos tratando da ordem econômica, da ordem convencional ou da ordem jurídica.

A ordem econômica, fundada no interesse, em especial o livre mercado (MWG I/23, cap. I, $\$ 4$, nota 3), implica sempre uma "adaptação externa" ou "adaptação planejada" [planmässige Anpassung]. As condiçóes impostas por quem se encontra na situação objetiva do mercado, ao estimular a adoção de uma estrita "racionalidade referente a fins nas ações", possuem um potencial de homogeneização [Gleichartigkeiten], regularidade [Regelmässigkeiten] e continuidade [Kontinuitäten] "que, em determinados casos, é até mais estável que ordens sociais munidas dos atributos das normas [Norm] e dos deveres [Pflicht]: "a orientação exclusiva pela orientação de interesses crus, sejam próprios ou alheios, produz efeitos análogos ao que se procura impor - muitas vezes em vão - pela sua normatização" (MWG I/23, cap. I, \$4, nota 3).

No entanto, ao falar de "normatização" já estamos tratando de outros tipos de estruturas sociais, quer dizer, das ordens convencionais e das ordens jurídicas. Como ambas nos remetem às normas e deveres, elas exercem seus efeitos macroestruturais de modo completamente diferente da ordem econômica. No caso da convenção, "a validade está garantida externamente pela chance de que um comportamento desviante no interior de um círculo determinado de pessoas acabará por esbarrar com uma reprovação (relativamente) geral e que pode ser sentida na prática" (MWG I/23, I, \$6). Já no direito, a legitimidade "está garantida externamente pela probabilidade de coação (física e psíquica) exercida por determinado quadro de pessoas cuja função específica consiste em forçar a observação dessa ordem ou castigar sua violação" (MWG I/23, I, \$6).

A sociologia da ordem convencional de Weber inclui diversos exemplos, como modos estabelecidos de saudação, formas de vestir-se, de preparar os alimentos, costumes estamentais ou mesmo um boicote organizado (MWG I/23, I, \$6, nota 1): todas elas são formas de ação cujo desvio implica como consequência a reprovação social. No entanto, dada a ausência de um grupo de pessoas destinado a garantir formalmente a observância das convenções, a iniciativa de constranger os indivíduos 
à conformidade é descentralizada e informal, podendo partir de qualquer indivíduo (ou de coletivo relativamente organizado, como no caso do boicote) pertencente a um círculo específico no qual aquelas convenções são vigentes.

Essa situação se modifica no caso da ordem jurídica, pois o que define esse fenômeno é "a existência de um quadro coativo" (MWG I/23, I, \$6, nota 2, ênfase do original) cuja função é a "imposição das regras jurídicas" (MWG I/23, I, \$6, nota 2, ênfase do original). Em épocas posteriores da história, esse aparato pode ser, por exemplo, o clã, os estatutos de uma associação, a autoridade do patriarca, uniões ou comunidades de companheiros. O que importa, na perspectiva da sociologia, é simplesmente a existência do aparato coativo, independente de quais sejam os meios empregados para a imposição das regras: "os meios de coação não vêm ao caso" (MWG I/23, I, $\$ 6$, nota 2, ênfase do original).

A conclusão a que Weber quer chegar é que, do ponto de vista estrutural, ordens sociais legítimas podem assumir a forma social da convenção e do direito, ambos entendidos como dois mecanismos das garantias externas das estruturas sociais.

\section{Fundamentos da legitimidade}

Enquanto o conceito de "garantias" de legitimidade nos colocava na perspectiva externa, quer dizer, aquela que privilegia os efeitos das estruturas sobre os indivíduos (direção macro-micro), com o conceito de "fundamentos" de legitimidade somos jogados em outra perspectiva, a saber, aquela que perfaz o movimento que vai do nível micro dos agentes até o nível macro das estruturas sociais. Não sem motivo, é o próprio Weber que afirma: "aqueles que atuam socialmente podem atribuir [Zuschreibung] validade legítima a uma ordem determinada” (MWG I/23, I, §7).

Esse processo de atribuição por parte dos agentes pode ocorrer por quatro vias diferentes: 1) em virtude da tradição; 2) em virtude da crença afetiva; 3) em virtude de uma crença racional referente a valores; ou 4) em virtude de um estatuto existente em cuja legalidade se acredita. Vale notar que o termo "crença" aparece apenas duas vezes e apenas no que diz respeito à crença afetiva e à crença em valores. Nas notas explicativas desse parágrafo, contudo, ao invés de explorar cada uma dessas quatro vias, Weber simplesmente retoma sua conhecida trilogia dos tipos de dominação. Ele não oferece qualquer justificativa sobre por que os quatro tipos de atribuição e os três tipos de dominação não correspondem entre si, ou, pelo menos, qual seria a relação entre eles.

Embora não aponte para nenhuma inovação ou diferença decisiva na exposição dos três tipos de dominação (em relação ao que está posto em seus demais textos), chama a atenção o fato de que Weber inicie sua exposição pela dominação tradicio- 
nal, passando muito brevemente pela dominação carismática, até chegar à fórmula contemporânea da dominação legal. Conforme essa sequência, "a crença no caráter sagrado da tradição é a forma mais universal e primitiva de legitimidade" (MWG I/23, I, $\$ 7$, nota 1$)$. A tradição possui um caráter eminentemente conservador, pois o medo de danos de origem mágica fortalece a inibição psíquica diante de todas as formas habituais e inveteradas de comportamento (MWG I/23, I, \$7, nota 1). Quebrar o poder da ordem estabelecida através da "criação consciente de novas ordens apresentou-se quase sempre na forma de oráculos proféticos” (MWG I/23, I, \$7, nota 2), praticamente a única referência que ele nos oferece da dominação carismática. Por fim, ele nos relembra que "a forma de legitimidade hoje predominante é a crença na legalidade" (MWG I/23, I, \$7, nota 4), que ele define como "obediência a preceitos jurídicos positivos estatuídos através de procedimento habitual e formalmente correto" (MWG I/23, I, $\$ 7$, nota 4 ).

Mas como explicar o fato de que, apesar da existência de quatro mecanismos subjetivos atributivos de crença, tenhamos concretamente apenas três tipos de dominação? Para explicar essa aparente discrepância, Breuer (2006) relembra que esse tópico de Economia e sociedade trata do conjunto das ordens sociais legítimas: ele é, pois, um tópico de sociologia geral [que trata das estruturas sociais em sentido amplo] e não de sociologia política [que trata apenas das estruturas políticas em particular]. A ordem política é um tipo de ordem social legítima, mas não é a única desse gênero. Por essa razão a descrição dos tipos de dominação deve ser entendida como uma exemplificação, quer dizer, como ilustração concreta de uma ordem social legitimada normativamente. Mas como as formas de dominação são apenas um caso em particular, não há razão para postular uma relação de correspondência exata entre os quatro motivos de atribuição (que dizem respeito às ordens sociais no sentido amplo) e os três tipos de dominação.

Apesar do valor dessa observação, podemos também ir além do sentido imediato do texto para explorar esta questão em perspectiva teórico-sistemática. É o que realiza Andrea Maurer (1999) quando propõe separar o (1) problema da "constituição" do (2) problema da "reprodução" das estruturas políticas. Dessa feita, enquanto o tópico das garantias da legitimidade, ao mostrar que a dominação assume a forma estrutural da convenção ou do direito, trata do problema da reprodução das ordens legítimas na esfera macro; o tópico dos fundamentos da legitimidade coloca a questão da gênese ou constituição da ordem legítima na sua dimensão microssocial. Do ponto de vista constitutivo, estruturas políticas (no nível macro) emergem de um problema cuja raiz deve ser localizada na esfera dos agentes sociais e no modo como eles atribuem validade às estruturas políticas. As crenças simbólicas que conferem legitimidade às ordens sociais legítimas, em particular aquelas de tipo político, não 
existem enquanto entidades que subsistem por si mesmas, pois residem em um sentido que precisa encontrar seu ancoradouro último nas relaçôes sociais: "a disposição de uma ou várias pessoas de se submeter à imposição de uma ordem [...] pressupõe a crença na autoridade em algum sentido legítima daquele ou daqueles que impõem essa ordem" (MWG I/23, I, $\$ 7$, nota 5).

\section{Considerações finais}

A sociologia weberiana da dominação é profundamente devedora da tradição kantiana e da famosa distinção entre ser [Sein] e dever-ser [Sollen]. Com efeito, a dimensão externo-coercitiva do direito e interno-imperativa das normas morais corta transversalmente toda a arquitetura da reflexão weberiana sobre o poder legítimo (Treiber, 1988). Por essa razão, essa dicotomia pode nos servir como um excelente guia para sintetizar os resultados da presente investigação. Podemos reconhecer a distinção interno/externo como operador analítico tanto na sociologia política [em sentido específico] quanto na sociologia compreensiva [em sentido geral] de Max Weber.

No âmbito da sociologia política, formas estáveis de poder político requerem tanto justificativas internas quanto meios externos: ambos são fatores co-constitutivos, com igual peso causal, na estruturação das formas de dominação. Em sua sociologia geral, Weber acrescenta a esse dado a conotação de que a legitimidade, enquanto elemento simbólico, é um fator vital do processo de institucionalização das estruturas sociais em geral e das estruturas políticas em particular. A legitimação, seja entendida como "justificativa" (conforme sua sociologia política), seja como algo que "deve ser válido" (ou Geltensollen - conforme sua sociologia geral), diz respeito à validade normativa das estruturas sociais e políticas na medida em que elas são consideradas modelares e obrigatórias para o agir social. Uma vez dotadas desse caráter prescritivo, estruturas e organizações políticas são reforçadas normativamente.

Não obstante, Weber nunca utiliza essa dicotomia de forma estanque. Ao abordar a diferença entre as garantias externas e os fundamentos internos da legitimidade, ele nos mostra que a legitimidade possui suas raízes na dimensão microssimbólica do sentido, pois são os agentes sociais que atribuem validez legítima à ordem política. Ao mesmo tempo, tais representações necessitam revestir-se de formas estruturais específicas, seja enquanto ordens convencionais, seja enquanto ordens jurídicas: ambas são modos diferenciados de institucionalização normativa das estruturas sociais. Pode-se concluir, portanto, que existe um nexo intrínseco entre o elemento simbólico e o elemento organizacional da dominação.

A distinção conceitual entre as justificativas internas e os fundamentos externos nos permite avançar no entendimento de como, concretamente, representações 
simbólicas, por um lado, e estruturas organizacionais, por outro, estão mutuamente articuladas nas formas da dominação. No modelo de Weber, a legitimidade [representações simbólicas] deve ser compreendida em suas várias dimensões que incluem, além do próprio (i) conteúdo simbólico das crenças coletivas, sua (ii) ancoragem interna nos processos atributivos da esfera microssocial [Fundamentos da legitimidade], bem como sua (ii) formalização externa [Garantias da legitimidade] na esfera macrossocial (Lepsius, 2009). Max Weber nos apresenta, pois, um modelo multidimensional para entender sociologicamente o complexo processo de legitimação das instituições políticas contemporâneas.

\section{Referências bibliográficas}

BADER, Veit-Michael. (1989), "Max Webers Begriff der Legitimität. Versuch einer systematisch-kritischen Rekonstruktion”. In: WeIss, Johannes (org.). Max Weber heute: Erträge und Probleme der Forschung. Frankfurt am Main, Suhrkamp, pp. 296-334.

Breuer, Stefan. (2006), Legitime Herrschaft. In: Breuer, Stefan. Max Webers tragische Soziologie: Aspekte und Perspektiven. Tübingen, Mohr Siebeck, 2006.

Breuer, Stefan. (2011), Herrschaft in der Soziologie Max Webers. Wiesbaden, Harrassowitz Verlag.

Greshoff, Rainer. (2006), “'Soziales Handeln' und 'Ordnung' als operative und strukturelle Komponente sozialer Beziehungen". In: LichtblaU, Klaus (org.). Max Webers Grundbegriffe: Kategorie der Kultur und sozialwissenschaftlichen Forschung. Wiesbaden, vs, pp. 243-257.

Habermas, Jürgen. (1992), Faktizität und Geltung: Beiträge zur Diskurstheorie des Rechts und des demokratischen Rechtsstaats. Frankfurt am Main, Suhrkamp.

Hanke, Edith. (2001), Max Webers Herrschaftssoziologie: Studien zu Entstehung und Wirkung. Tübingen, Mohr Siebeck.

HANke, Edith. (2013), “Nachwort der Herausgeberin”. In: [MWG I/23] Weber, Max. Wirtschaft und Gesellschaft. Soziologie. Unvollendet 1919-1920 [Economia e sociedade. Sociologia. Inacabados 1919-1920]. Organização de K. Borchardt, E. Hanke e W. Schluchter. Tübingen, Mohr Siebeck, pp. 230-278.

Lepsius, Mario Rainer. (2009), Interessen, Ideen und Institutionen. Wiesbaden, vs Verl. für Sozialwiss.

Lüвве, Weyma. (1991), Legitimität kraft Legalität: Sinnverstehen und Institutionenanalyse bei Max Weber und seinen Kritikern. Tübingen, Mohr Siebeck.

MAURER, Andrea. (1999), Herrschaft und soziale Ordnung: kritische Rekonstruktion und Weiterführung der individualistischen Theorietradition. Opladen, Westdt.

Merquior, José Guilherme. (1990), Rousseau e Weber: dois estudos sobre a teoria da legitimidade. Rio de Janeiro, Guanabara. 
Prewo, Rainer. (1979), Max Webers Wissenschaftsprogramm: Versuch einer methodischen Neuerschließung. Frankfurt am Main, Suhrkamp.

Schluchter, Wolfgang. (1998), Religion und Lebensführung. Frankfurt am Main, Suhkamp. Schluchter, Wolfgang. (2015), Grundlegungen der Soziologie: eine Theoriegeschichte in systematischer Absicht. Tübingen, Mohr Siebeck.

Schluchter, Wolfgang. (2016), Max Webers späte Soziologie. Tübingen, Mohr Siebeck.

Schwinn, Thomas. (1993), "Max Webers Konzeption des Mikro-Makro Problems”. Kölner Zeitschrift für Soziologie und Sozialpsychologie, 45: 220-237.

Schwinn, Thomas. (2014), “Ordnung”. In: Müller, Hans-Peter \& Sigmund, Steffen (orgs.). Max-Weber-Handbuch, Stuttgart, J. B. Metzler, pp. 98-100.

STACHURA, Mateusz. (2008), "Einleitung der Standort weberianischer Institutionentheorie im Raum konkurrierender Forschungsprogramme". In: STAChura, Mateusz; Bienfait, Agathe; Albert, Gert; Sigmund, Steffen (orgs.). Der Sinn der Institutionen. vs Verlag für Sozialwissenschaften, pp. 8-39.

Treiber, Hubert. (1988), “Im 'Schatten' des Neukantianismus. Norm und Geltung bei Max Weber”. In: BRANDT, Jiirgen \& STREMPEL, Dieter (orgs.). Soziologie des Rechts. Festschrift für Erhard Blankenburg zum 60. Baden-Baden, Nomos.

[MWg i/17] Weber, Max. (1992), Wissenschaft als Beruf 1917/1919 - Politik als Beruf 1919 [Ciência como profissão 1917/1919 - Política como profissão 1919]. Organização de W. Schluchter, com colaboração de B. Morgenbrod. Tübingen, Mohr Siebeck.

[MWG I/18] Weber, Max. (2018), Verstehende Soziologie und Werturteilsfreiheit: Schriften und Reden 1908-1917. Organizado por Johannes Weiss em conjunto com Sabine Frommer. Tübingen, Mohr Siebeck.

[MWG I/23] Weber, Max. (2013), Wirtschaft und Gesellschaft. Soziologie. Unvollendet 1919-1920

[Economia e sociedade. Sociologia. Inacabados 1919-1920]. Organização de K. Borchardt,

E. Hanke e W. Schluchter. Tübingen, Mohr Siebeck, pp. 230-278.

[MWg I/24] Weber, Max. (2009), Wirtschaft und Gesellschaft. Entstehungsgeschichte und Dokumente. Editado por Wolfgang Schluchter. Tübingen, Mohr Siebeck.

[MWG II/9] WebER, Max. (2008), Briefe 1915-1917. Editado por Gerd Krumeich e M. Rainer Lepsius, em conjunto com Birgit Rudhard e Manfred Schön. Tübingen, Mohr Siebeck, p. XxxI.

\section{Resumo}

Garantias externas e fundamentos internos: dimensões da legitimidade em Max Weber O artigo propõe uma reconstrução histórico-sistemática do conceito de legitimidade no âmbito do pensamento político e sociológico de Max Weber. Na primeira parte (histórica), contrapondo-se à tese de que haveria uma ruptura no pensamento de Weber, argumenta-se que a dimensão estrutural e a dimensão simbólica são variáveis que possuem o mesmo peso analítico na determinação 
teórica das formas de dominação. Na segunda parte (sistemática), após demonstrar o conteúdo prescritivo e normativo inerente ao conceito de legitimidade, ele será examinado ainda na sua dimensão macrossocial, enquanto "garantia de legitimidade", e na sua dimensão microssocial, enquanto "fundamento da legitimidade". Ao separar analiticamente cada um desses aspectos, Weber nos legou os alicerces de um conceito multidimensional de legitimidade que estabelece um elo intrínseco entre as estruturas políticas e seus fundamentos normativos.

Palavras-chave: Max Weber; Legitimidade; Crenças; Instituições; Validade.

\section{Abstract}

External guarantees and internal fundamentals: dimensions of legitimacy in Max Weber

The article proposes a historical-systematic reconstruction of the concept of legitimacy in Max Weber's political and sociological thought. In the first (historical) part, opposing the thesis that there would be a rupture in Weber's thought, it is argued that the structural dimension and the symbolic dimension are variables that have the same analytical weight in the theoretical determination of forms of domination. In the second (systematic) part, after demonstrating the prescriptive and normative content inherent in the concept of legitimacy, it will also be examined in its macro-social dimension, as a "guarantee of legitimacy", and in its micro-social dimension, as "the foundation of legitimacy". By analytically separating each of these aspects, Weber bequeathed us the foundations of a multi-dimensional concept of legitimacy that establishes an intrinsic link between political structures and their normative foundations.

Keywords: Max Weber; Legitimacy; Beliefs; Institutions; Validity.

Texto recebido em 23/06/2021 e aprovado em 21/09/2021.

DOI: 10.11606/0103-2070.ts.2021.187639

Carlos Eduardo Sell é doutor em Sociologia Política e professor do Departamento de Sociologia e Ciência Política da Universidade Federal de Santa Catarina, UfSC. Realizou dois estágios de pós-doutorado em Heidelberg em 2011-2012 e 2017-2018. E-mail: carlos.sell@ufsc.br. 